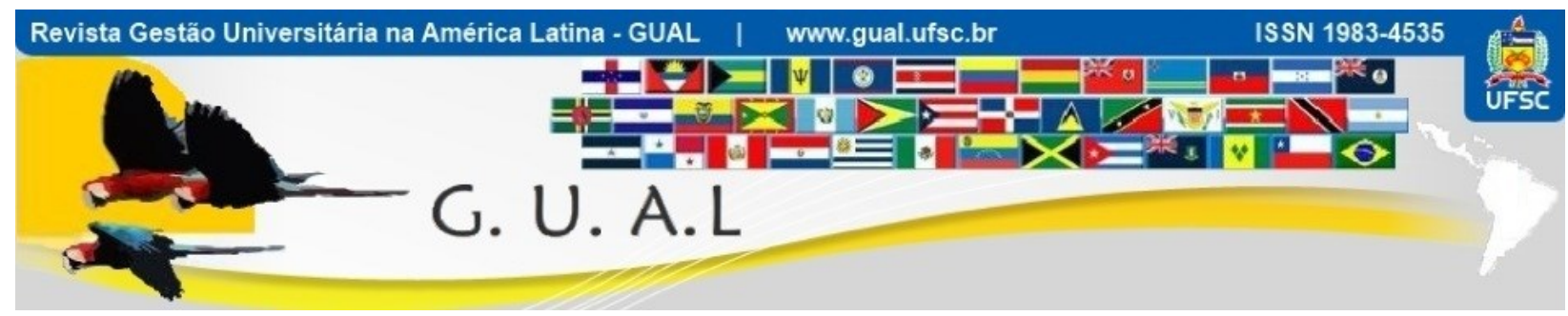

DOI: http://dx.doi.org/10.5007/1983-4535.2017v10n1p172

\title{
O ABSENTEÍSMO ACADÊMICO E SUAS CONSEQUÊNCIAS MAIS ÓBVIAS
}

THE ACADEMIC ABSENTEEISM AND ITS MORE OBVIOUS RESULTS

Gilberto José Miranda, Doutor

Universidade Federal de Uberlândia - UFU

gilbertojm@facic.ufu.br

Tamires Sousa Araujo, Doutoranda Universidade Federal de Uberlândia - UFU tamiresousa124@hotmail.com

Izabelle Almeida Marcelino, Graduada Universidade Federal de Uberlândia - UFU izabelle_marcelino@hotmail.com

Recebido em 30/agosto/2015

Aprovado em 07/novembro/2016

Sistema de Avaliação: Double Blind Review

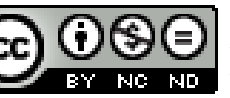

Esta obra está sob uma Licença Creative Commons Atribuição-Uso. 


\title{
RESUMO
}

A presente pesquisa teve como propósito analisar a relação entre absenteísmo e desempenho acadêmico no Curso de Ciências Contábeis. Para tanto, foi realizada uma pesquisa documental em uma Instituição Pública brasileira. Com a permissão da coordenação do curso, foram analisadas diversas informações relativas à participação de 1.525 estudantes em 715 disciplinas ministradas no período compreendido entre o primeiro semestre de 2009 e o segundo semestre de 2013, totalizando 29.839 observações. A partir dessas observações, foram analisadas as seguintes variáveis: desempenho acadêmico, tamanho da turma, período, turno, carga horária e inassiduidade (medida de absenteísmo). Os resultados indicaram que todas as variáveis investigadas estão significativamente correlacionadas ao desempenho acadêmico dos estudantes. No entanto, a variável que apresentou a correlação mais forte foi absenteísmo. Esses resultados sugerem que a primeira consequência do absenteísmo é a queda no desempenho acadêmico, como já havia sido identificado anteriormente por outros pesquisadores. Também foi identificado que o absenteísmo está significativamente correlacionado com todas as variáveis acima mencionadas. Assim, alunos que estão em salas mais cheias, do turno diurno, dos períodos finais e matriculados em disciplinas com cargashorárias maiores tendem a apresentar maiores níveis de absenteísmo. Além disso, constatouse que, $32,9 \%$ dos alunos evadidos no período pesquisado haviam tido reprovações por falta entre 2009 e 2013, evidenciado assim, a segunda consequência grave do absenteísmo, a evasão.

Palavras-chave: Absenteísmo. Desempenho acadêmico. Evasão. Ciências Contábeis.

\begin{abstract}
This study aimed to analyze the relationship between absenteeism and academic performance in the Accounting Sciences Course. For this purpose, a documentary research was realized in a Brazilian public institution. With the course coordination permission, several information were analyzed concerning the participation of 1,525 students in 715 courses taught in the period between the first semester of 2009 and the second semester of 2013, totaling 29,839 observations. From these observations, the following variables were analyzed: academic performance, class size, period, turn, course load and not assiduous (absenteeism measure). The results indicated that all the variables investigated are significantly correlated to academic performance of students. However, the variable that had the strongest correlation was absenteeism. These results suggest that the first consequence of absenteeism is the decline in academic performance, as had been previously identified by other researchers. It was also identified that absenteeism is significantly correlated with all the variables mentioned before. Thus, students who are in more filled rooms, of the day turn, of the final periods and enrolled in courses with higher course loads tend to have higher absenteeism levels. In addition, it was found that $32.9 \%$ of evaded students in the period researched had had reproofs for lack between 2009 and 2013, evidenced thereby, the second serious consequence of absenteeism, the evasion.
\end{abstract}

Key words: Absenteeism. Academic performance. Evasion. Accounting Sciences. 


\section{INTRODUÇÃO}

Há muitos fatores que influenciam o desempenho acadêmico dos discentes, como aspectos relativos à família, ao trabalho, aos métodos de ensino dos professores, entre outros (SOUTO-MAIOR et al., 2011). Segundo Munhoz (2004), o desempenho acadêmico é a atuação de um indivíduo ou de um grupo de pessoas no desenvolvimento de determinada atividade, avaliando-se a eficiência e rendimentos com o intuito de demonstrar as habilidades e o conhecimento.

Compreender quais são os determinantes do desempenho acadêmico pode ser uma questão crucial para o aprimoramento do processo de ensino e aprendizagem. Estudos no campo da Contabilidade têm evidenciado que variáveis relativas aos discentes como: tamanho da turma, período, turno, carga horária, entre outras estão relacionadas ao desempenho dos discentes (MIRANDA et al., 2015).

O absenteísmo, que se refere à ausência do aluno às aulas presenciais, foco deste estudo, tem sido tomado, pelo senso comum, como uma das principais causas do baixo desempenho escolar. Alguns autores (SOUTO-MAIOR, 2011; GONZÁLEZ, 2014) alegam que a questão das faltas escolares pode estar associada à motivação dos alunos.

Nesse sentido, Steenkamp, Baard e Frick (2009) entendem que é importante motivar os alunos no primeiro ano da faculdade, já que, nesse período, ocorre a transição do ensino médio para o ensino superior. Alunos motivados são mais empenhados e faltam menos, melhorando, consequentemente, o desempenho acadêmico, afirmam os autores.

Embora não haja consenso entre os estudiosos que tratam o absenteísmo acadêmico e sua relação com o desempenho discente, a maioria das pesquisas aponta associações negativas entre desempenho acadêmico e absenteísmo (GONZÁLEZ, 2014; NOGUEIRA et al, 2012; SOUTO-MAIOR, 2011). Todavia, no campo da Contabilidade as pesquisas sobre a temática ainda são escassas.

Diante desse contexto, o presente trabalho tem como objetivo analisar a relação entre o absenteísmo e o desempenho acadêmico no curso de Ciências Contábeis de uma Universidade Pública brasileira, visando a esclarecer se, de fato, a presença em sala guarda alguma relação com a obtenção de notas mais altas na área contábil.

Para alcance desse propósito, foram necessários os seguintes objetivos específicos: i) caracterizar a amostra pesquisada; ii) analisar as correlações existentes entre as variáveis desempenho acadêmico, tamanho da turma, período, turno, carga horária e ausência em sala 
de aula (medida de absenteísmo); iii) analisar os níveis de evasão por tipo de reprovação nas disciplinas (reprovação por nota e reprovação por frequência).

Estudos que abordam temas voltados à educação acadêmica e que buscam alternativas que melhorem o ensino são importantes para o aprimoramento do processo de ensino e aprendizagem. Faro (2007) evidencia que o absenteísmo acadêmico é um empecilho para o sucesso escolar do discente, ficando evidente a necessidade de estudos que abordem tal temática.

Justifica-se estudar o tema absenteísmo no âmbito do ensino superior público, pois a falta de freqüência dos discentes é um assunto pouco discutido, e uma maior discussão pode levar à elaboração de mecanismos para tentar inibir as faltas dos discentes e suas consequências. No campo da contabilidade, especificamente, ainda há poucos estudos, notadamente, sobre absenteísmo, dificultando a melhoria da relação entre professores e alunos.

\section{FUNDAMENTAÇÃO TEÓRICA}

\subsection{DESEMPENHO ACADÊMICO E ABSENTEÍSMO}

Para avaliar o rendimento de um aluno, é preciso determinar as formas de mensurar o desempenho acadêmico. Segundo Munhoz (2004), o desempenho discente abrange a dimensão da ação, atuação e execução de uma atividade, que será analisada para avaliar a necessidade de ajustes, sendo o resultado expresso em forma de nota ou conceito.

Para Araújo, Camargos e Camargos (2011), o resultado expresso em forma de nota ou conceito não é o método mais confiável para se analisar o desempenho acadêmico, pois não aprofunda os aspectos que facilitam ou dificultam a aprendizagem dos discentes. Entretanto, segundo os autores, a nota objetiva e imparcial é um dos melhores métodos que se têm para analisar o desempenho acadêmico de uma amostra grande, já que é complicado analisar com precisão todos os fatores que afetam o rendimento dos discentes e a relação com as notas obtidas.

Segundo Miranda et al. (2015), há vários fatores que afetam o desempenho acadêmico, tais como, aspectos relativos ao corpo docente, ou seja, atributos dos próprios discentes e características das instituições de ensino, que englobam não só a infraestrutura, mas a organização didático-pedagógico e o corpo docente. Com uma abordagem diferente, mas enfocando praticamente as mesmas variáveis, Araújo, Camargos e Camargos (2011) 


\section{O ABSENTEÍSMO ACADÊMICO E SUAS CONSEQUÊNCIAS MAIS ÓBVIAS DOI: http://dx.doi.org/10.5007/1983-4535.2017v10n1p172}

entendem que, entre os fatores que afetam o aprendizado, encontram-se os problemas sociais, demográficos, econômicos, a forma de os docentes ministrarem a disciplina e o espaço físico.

No entanto, são raras as possibilidades de pesquisas envolvendo todas as variáveis que afetam o desempenho acadêmico. Alguns fatores são mais fáceis de serem mensurados, como a infraestrutura das salas de aulas, materiais disponibilizados e recursos tecnológicos (MIRANDA et al., 2015). As várias pesquisas empreendidas pelo Sistema Nacional de Avaliação do Desempenho Superior (SINAES) também tornam possíveis estudos sobre alguns aspectos específicos, já que, periodicamente, tais levantamentos são realizados em todo o território nacional. Existem outras variáveis associadas ao desempenho acadêmico mas não captadas pelo SINAES, como: depressão, tendência a culpar os outros pelos seus erros, uso de álcool, estilos de estudo, atitude e motivação (SOUTO-MAIOR et al., 2011). Além dessas, destaca-se o absenteísmo, uma vez que não há uma integração de bancos de dados que permita estudos mais amplos sobre esse comportamento.

O que se sabe é que é a ausência aos bancos escolares é um fenômeno antigo, que vem mudando ao longo dos anos. As razões das infrequências dos estudantes de hoje, certamente não são as mesmas do passado. No século XIV, era comum os alunos faltarem às aulas em virtude de guerras e doenças, enquanto, atualmente, é menos óbvio e mais difícil identificar as razões da ausência (RODGERS, 2001).

Segundo González (2014), a forma mais comum de absenteísmo é a ausência às aulas. No entanto, há outra forma de se abster, mais complexa e difícil de ser mensurada, tendo em vista que, mesmo estando presente fisicamente na sala de aula, o aluno não participa das atividades realizadas e não presta atenção no conteúdo ministrado pelo professor. Segundo o autor, a falta de motivação por parte do aluno é o primeiro passo para a inassiduidade, pois experiências negativas e o desinteresse pelas aulas fazem com que os alunos se desmotivem e comecem a chegar mais tarde e sair mais cedo, distanciando-se progressivamente da faculdade.

Para Schmulian e Coetzee (2011), a ausência ocorre por alguns motivos, desde razões como doença e trabalho, até dormir tarde e ir a festas. De acordo com os autores, os próprios alunos acreditam que a presença influencia diretamente no desempenho acadêmico, pois a frequência regular melhora o entendimento e a compreensão do material didático.

As principais razões do absenteísmo apontadas pelos alunos são: confronto no calendário (principalmente, quem repete matéria), estudar para outra disciplina (prova), problemas no transporte e dormir demais (SHMULIAN; COETZEE, 2011). Já Paisey e 


\section{O ABSENTEÍSMO ACADÊMICO E SUAS CONSEQUÊNCIAS MAIS ÓBVIAS DOI: http://dx.doi.org/10.5007/1983-4535.2017v10n1p172}

Paisey (2004) entendem que os principais motivos apontados pelos alunos são: trabalhos do curso, doenças, problemas pessoais e trabalho em tempo parcial.

O trabalho em tempo parcial, como os estágios, pode gerar muita pressão sobre os alunos, pois muitos empresários atribuem várias funções e atividades aos estagiários, fazendo com que o aluno se ausente cada vez mais da sala de aula, sendo eles, ainda, em alguns casos, tratados como funcionários regulares, notadamente, na área contábil. Assim, cada vez mais esses estudantes faltam às aulas para participarem de cursos oferecidos pelas empresas, empenhando-se mais nas atividades relativas ao trabalho (SANCOVSCHI, FERNANDES, SIQUEIRA, 2009).

Para Romer (1993), o fato de os alunos se ausentarem das aulas pode ser uma opção, por acharem que as aulas ministradas agregam pouco conhecimento e o ensino é de baixa qualidade. Para eles, o material disponibilizado pelo professor é suficiente para aprender sozinho, podendo aprender até mais estudando em outro lugar com o mesmo tempo gasto em sala de aula. Dessa maneira, muitos alunos faltam pelo simples fato de considerarem as aulas como um "desperdício" de tempo, e a presença, como desnecessária para a obtenção do conhecimento.

De qualquer forma, a ideia predominante no meio acadêmico e no senso comum é de que o absenteísmo é prejudicial ao desempenho acadêmico. Nesse sentido, para combater o absenteísmo, é fundamental que o docente conheça o aluno e busque alternativas de ensino para estimular o aprendizado, já que muitos casos de absenteísmo estão relacionados à desmotivação e desinteresse pelas aulas. Uma maneira encontrada de incentivar os alunos e melhorar o ensino é apresentar exemplos mais práticos e parecidos com aqueles do ambiente profissional, mostrando a importância da disciplina ministrada (GONZÁLEZ, 2014).

Um método encontrado por Stuart (2004) é o feedback explicativo, pois, segundo o autor, o mais importante não é o exercício e a prática, mas, sim, o feedback, já que a avaliação e a resposta imediata após cada atividade contribuem para que o estudante melhore o desempenho e se corrijam os possíveis erros. Assim, fundamental é a presença do professor em sala de aula, principalmente, com a finalidade de orientar os alunos para o melhor caminho para a realização de determinada atividade e a aplicação de distintos métodos de ensino.

Mesmo disponibilizando o conteúdo apresentado em sala de aula, a presença continua sendo muito importante para a compreensão e pelas diferentes formas com que o docente ministra o conteúdo programado, possibilitando o esclarecimento de eventuais problemas e 
solucionando os exercícios de forma mais clara e objetiva. Foi verificado no estudo de SoutoMaior (2011), na disciplina Pesquisa Operacional dos cursos de Administração e Contabilidade da Universidade Federal de Santa Catarina, que a quantidade de faltas e o desempenho acadêmico são inversamente proporcionais.

No estudo de Schmulian e Coetzee (2011), também foram encontradas evidências de que o desempenho e absenteísmo estão negativamente correlacionados. No referido estudo, foram analisados dois cursos de contabilidade em uma universidade na África do Sul e outro, na Escócia. Foi aplicado o mesmo questionário nas duas instituições e verificado que, mesmo sendo lugares completamente diferentes e as razões do absenteísmo serem distintas, o resultado foi o mesmo. Isso confirma a importância da presença do aluno em sala de aula para melhorar o desempenho, acreditando os próprios discentes que a presença afeta de forma negativa o resultado final.

Segundo Teixeira (2013), a ausência do aluno em sala de aula pode fazer com que ele não saiba responder determinada questão da prova por não ter se inteirado do conteúdo. Assim, de acordo com Nogueira et al. (2012); Rodgers (2001); Romer (1993); Miranda et al. (2015) o absenteísmo apresenta uma relação inversa com o desempenho acadêmico, visto que, quanto maior o número de faltas, menor o desempenho acadêmico.

Ao contrário da maioria dos artigos analisados, na pesquisa realizada em uma faculdade particular de Belo Horizonte, no curso de Ciências Contábeis, por Araújo, Camargos e Camargos (2011), a relação entre o número de faltas e desempenho acadêmico apresentou uma relação positiva. A justificativa, segundo os autores, é de que os alunos que faltam, principalmente em virtude do trabalho, se empenham mais para acompanhar a matéria, têm mais responsabilidades e estudam mais para compreender o conteúdo perdido.

Em síntese, na lacuna representada pelas contradições dos poucos estudos no tocante à influência do absenteísmo no desempenho estudantil na área contábil, o presente estudo se situa, partindo-se da hipótese de que existe associação estatisticamente significativa entre essas duas variáveis.

\section{ASPECTOS METODOLÓGICOS}

O presente estudo é descritivo, uma vez que tem o propósito de investigar os atributos desempenho acadêmico, tamanho da turma, período, turno, carga horária e ausência da sala de aula dos estudantes do curso de Ciências Contábeis de uma universidade pública brasileira. Segundo Gil (1999, p. 44), "pesquisas deste tipo têm como objetivo primordial a descrição 
das características de determinada população ou fenômeno ou o estabelecimento de relações entre variáveis".

Sua classificação, quanto à abordagem do problema é quantitativa, que se caracteriza pelo emprego de variáveis quantitativas e uso instrumentos estatísticos no tratamento dos dados (RICHARDSON, 2011). A coleta de dados foi documental, tendo sido os mesmos obtidos junto à coordenação do curso de Ciências Contábeis de uma Universidade Pública brasileira. Foram coletados relatórios com informações de cada disciplina nos turnos diurno e noturno, oferecidos pela universidade, no período de 2009 a 2013. Os relatórios coletados continham as informações de cada aluno como: nome da disciplina, semestre/ano, nota final, carga horária, quantidade de faltas e vagas ocupadas.

O curso tem duração de cinco anos, sendo dividido em dez períodos. Cada período tem, em média, cinco disciplinas com carga horária de 60 horas. O turno diurno começou a ser oferecido pela universidade em 2009, portanto nem todas as disciplinas desse turno apresentam informações em todos os períodos. Dessa forma, foram analisadas as participações de 1.525 alunos em 715 disciplinas do primeiro semestre de 2009 ao segundo semestre de 2013, sendo 270 disciplinas do turno diurno e 445 disciplinas do turno noturno. A distribuição dessas disciplinas pode ser visualizada na Tabela 1:

Tabela 1 Composição da Amostra.

\begin{tabular}{lcccc}
\hline \multirow{2}{*}{ Semestre/Ano } & \multicolumn{2}{c}{ Quantidade de Disciplinas } & \multicolumn{2}{c}{ Quantidade de observações } \\
\cline { 2 - 5 } & Diurno & Noturno & Diurno & Noturno \\
\hline $1^{\circ}$ Semestre/2009 & 05 & 40 & 219 & 1.735 \\
$2^{\circ}$ Semestre/2009 & 10 & 42 & 416 & 1.794 \\
$1^{\circ}$ Semestre/2010 & 15 & 43 & 651 & 1.932 \\
$2^{\circ}$ Semestre/2010 & 21 & 45 & 819 & 1.862 \\
$1^{\circ}$ Semestre/2011 & 26 & 46 & 1.049 & 1.981 \\
$2^{\circ}$ Semestre/2011 & 30 & 45 & 1.222 & 2.035 \\
$1^{\circ}$ Semestre/2012 & 36 & 46 & 1.333 & 2.050 \\
$2^{\circ}$ Semestre/2012 & 40 & 46 & 1.382 & 2.035 \\
$1^{\circ}$ Semestre/2013 & 43 & 46 & 1.579 & 2.043 \\
$2^{\circ}$ Semestre/2013 & 44 & 46 & 1.617 & 2.085 \\
\hline Total & 270 & 445 & 10.287 & 19.552 \\
\hline
\end{tabular}

Fonte: Dados da Pesquisa.

As turmas tinham, em média, 42 alunos. Assim, a amostra final ficou composta por 29.839 observações. Nos relatórios de cada disciplina analisada, foram coletadas as seguintes informações: semestre/ano; número da matrícula do aluno; média final; código da disciplina e turma; quantidade de vagas ocupadas; carga horária total; e número de faltas. 
O foco da pesquisa é a relação entre desempenho acadêmico e absenteísmo. No entanto, outras variáveis relacionadas ao desempenho acadêmico que vêm sendo demonstradas pela literatura, quais sejam: "tamanho da turma", "turno", "período", "cargahorária da disciplina" (MIRANDA et al, 2015) foram analisadas também, para servirem de parâmetro para as análises. A Tabela 2 apresenta as variáveis pesquisadas:

Tabela 2 Descrição das variáveis utilizadas nos testes de correlação.

\begin{tabular}{|c|c|c|}
\hline Variável & Descrição & Mensuração \\
\hline Desempenho & $\begin{array}{l}\text { Notas obtidas pelos alunos em cada } \\
\text { disciplina por semestre. }\end{array}$ & Contínua, variando de 0 a 100. \\
\hline Tamanho da Turma & $\begin{array}{l}\text { Quantidade de alunos matriculados em cada } \\
\text { disciplina por semestre. }\end{array}$ & Discreta, variando de 4 a 60. \\
\hline Absenteísmo & $\begin{array}{l}\text { Fração das aulas semestrais perdida por } \\
\text { ausência. }\end{array}$ & Contínua, variando de 0 a 1. \\
\hline Turno & $\begin{array}{l}\text { Se refere ao turno no qual o estudante está } \\
\text { matriculado. }\end{array}$ & $\begin{array}{l}\text { Binária na qual } 1 \text { corresponde ao turno } \\
\text { noturno e } 0 \text { corresponde ao turno } \\
\text { integral. }\end{array}$ \\
\hline Período & $\begin{array}{l}\text { Se refere ao período no qual o estudante está } \\
\text { matriculado: (ingressantes) alunos } \\
\text { matriculados até o quinto período; } \\
\text { (concluintes) alunos matriculados do se } \\
\text { xto ao décimo período. }\end{array}$ & $\begin{array}{l}\text { Binária na qual } 1 \text { corresponde aos } \\
\text { alunos concluintes e } 0 \text { corresponde aos } \\
\text { alunos ingressantes. }\end{array}$ \\
\hline $\mathrm{CH} 30$ & Carga-horária da disciplina. & $\begin{array}{l}\text { Binária na qual } 1 \text { corresponde à carga- } \\
\text { horária de } 30 \text { horas e } 0 \text { corresponde às } \\
\text { demais cargas-horárias. }\end{array}$ \\
\hline CH60 & Carga-horária da disciplina. & $\begin{array}{l}\text { Binária na qual } 1 \text { corresponde à carga- } \\
\text { horária de } 60 \text { horas e } 0 \text { corresponde às } \\
\text { demais cargas-horárias. }\end{array}$ \\
\hline CH90 & Carga-horária da disciplina. & $\begin{array}{l}\text { Binária na qual } 1 \text { corresponde à carga- } \\
\text { horária de } 90 \text { horas e } 0 \text { corresponde às } \\
\text { demais cargas-horárias. }\end{array}$ \\
\hline
\end{tabular}

Fonte: Elaboração própria.

Para tratamento dos dados, foi feita, inicialmente, a descrição da amostra. Posteriormente, por meio do teste Kolmogorov-Smirnov, foi constatado que a amostra não possuía distribuição normal. Por fim, foi realizado o teste de correlação de Spearman.

\section{RESULTADOS}

Para apresentação dos resultados, foi feita a descrição da amostra, seguida dos testes de correlação entre as variáveis pesquisas. A Tabela 3 apresenta a quantidade de observações (aluno por disciplina) por turno. 
Tabela 3 Observações por Turno.

\begin{tabular}{lll}
\hline Turno & Quantidade & $\%$ \\
\hline Noturno & 19.552 & $65,52 \%$ \\
Diurno & 10.287 & $34,48 \%$ \\
\hline Total & 29.839 & $100,00 \%$ \\
\hline
\end{tabular}

Fonte: Dados da Pesquisa.

Como pode ser notado, o turno noturno apresentou praticamente o dobro de observações do turno diurno. Isso ocorre porque o curso diurno da instituição analisada foi criado em 2009. Desse modo, nem todas as disciplinas eram ministradas nos dois turnos no espaço temporal pesquisado. No primeiro semestre de 2009, por exemplo, existiam apenas o primeiro período do turno diurno e dez períodos do turno noturno. Mas com o passar do tempo os períodos do turno diurno foram aumentando. Assim, a quantidade de alunos e disciplinas do noturno são superiores ao diurno.

A Tabela 4 apresenta o tamanho das turmas investigadas. Embora a média geral fosse de, aproximadamente, 42 alunos, existiam turmas com distintos tamanhos.

Tabela 4 Tamanho das Turmas.

\begin{tabular}{lc}
\hline Tamanho & Quantidade $\%$ \\
\hline Até 40 alunos & $29,17 \%$ \\
De 41 a 50 alunos & $58,04 \%$ \\
De 51 a 60 alunos & $12,78 \%$ \\
\hline Total & $100,00 \%$ \\
\hline
\end{tabular}

Fonte: Dados da Pesquisa.

A maior parte das turmas $(58,04 \%)$ apresenta quantidade de alunos entre 41 e 50 estudantes, já que, a cada semestre, ingressam 40 novos alunos. A eles se somam os alunos reprovados em períodos anteriores, que deixaram de fazer a disciplina em seu período ou estudantes que vieram por transferência de outro curso.

A Tabela 5 apresenta a situação dos alunos após a conclusão das disciplinas pesquisadas.

Tabela 5 Desempenho por Discente.

\begin{tabular}{lcc}
\hline Situação & Quantidade & Quantidade $\%$ \\
\hline Aprovado & 24.835 & $83,23 \%$ \\
Dispensado & 72 & $0,24 \%$ \\
Trancamento Parcial & 233 & $0,78 \%$ \\
Reprovado por Nota & 2.515 & $8,43 \%$ \\
Reprovado por Frequência & 2.184 & $7,32 \%$ \\
\hline Total & 29.839 & $100,00 \%$ \\
\hline
\end{tabular}

Fonte: Dados da Pesquisa. 
O percentual total de alunos aprovados por disciplina cursada foi de $83,2 \%$ entre os anos de 2009 e 2013. Pode-se verificar, também, que houve 2.184 reprovações em virtude do absenteísmo, pois os alunos não comparecerem a pelo menos $75 \%$ das aulas, que é o mínimo exigido para aprovação. Menos de $1 \%$ dos casos se referem a trancamento parcial, que acontece quando o aluno se matricula em determinada disciplina, mas desiste no começo das aulas, por meio de solicitação formal à coordenação do curso, assim não afeta o desempenho final. Segundo Araújo, Camargos e Camargos (2011), o trancamento pode ser determinado pela dificuldade de alguns discentes conseguirem a nota mínima para aprovação.

A Tabela 6 detalha as frequências dos alunos que obtiveram aprovações, ou seja, 24.835 casos.

Tabela 6 Quantidades de Faltas dos Alunos Aprovados.

\begin{tabular}{lll}
\hline Faixas & Quantidade & Quantidade $\%$ \\
\hline Sem faltas & 5.972 & $24,05 \%$ \\
Até $5 \%$ de faltas & 3.788 & $15,25 \%$ \\
De $6 \%$ a $10 \%$ de faltas & 6.399 & $25,77 \%$ \\
De 11 a $15 \%$ de faltas & 4.599 & $18,52 \%$ \\
De 16 a $20 \%$ de faltas & 2.651 & $10,67 \%$ \\
De 21 a $25 \%$ de faltas & 1.426 & $5,744 \%$ \\
\hline Total & 24.835 & $100,00 \%$ \\
\hline
\end{tabular}

Fonte: Dados da Pesquisa.

É importante destacar que praticamente $1 / 4$ dos casos pesquisados não tiveram faltas em alguma nas disciplinas pesquisadas, ou seja, absenteísmo zero. Além disso, mais de 40\% dos alunos tiveram no máximo $10 \%$ de faltas e apenas 5,7\% dos casos ficaram no limite, ou seja, estiveram ausentes entre 21 a $25 \%$ das aulas.

O Gráfico 1 apresenta uma comparação entre os percentuais de absenteísmos dos alunos aprovados (conf. Tabela 5) de forma comparada aos percentuais de absenteísmos dos alunos Reprovados por Nota. 


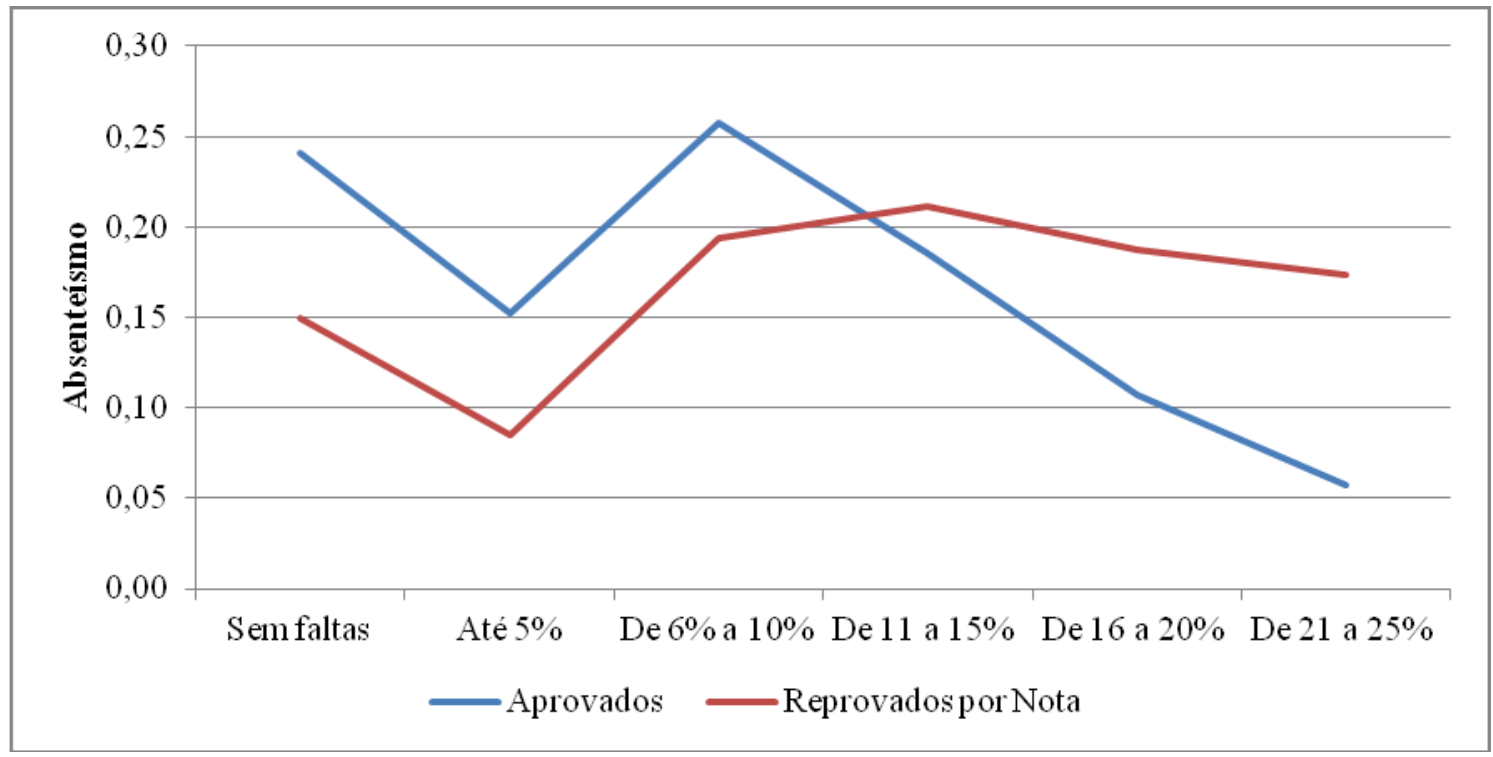

Gráfico 1 Absenteísmo Percentual - Alunos Aprovados versus Alunos Reprovados por Nota. Fonte: Dados da pesquisa.

Como pode ser observado no Gráfico 1, os percentuais de absenteísmo inferiores a $10 \%$ são maiores entre os alunos aprovados. Já os percentuais de inassiduidade superiores a $10 \%$ são maiores entre os alunos reprovados por nota. Em outras palavras, os alunos aprovados são mais frequentes que os alunos reprovados por nota. A fim de confirmar este entendimento, na Tabela 7, são apresentadas as correlações entre as variáveis em estudo.

Tabela 7 Correlação de Spearman.

\begin{tabular}{|c|c|c|c|c|c|c|c|c|c|}
\hline Variáveis & Itens & Desempenho & $\begin{array}{l}\text { Tamanho } \\
\text { da Turma }\end{array}$ & Absenteísmo & Turno & Período & $\mathrm{CH} 30$ & CH60 & CH90 \\
\hline Desempenho & $\begin{array}{l}\text { Coeficiente Correlação } \\
\text { P-valor } \\
\text { N }\end{array}$ & $\begin{array}{l}1 \\
29534\end{array}$ & & & & & & & \\
\hline he $\mathrm{da}$ & Coeficiente Correlação & $-0,107 * *$ & 1 & & & & & & \\
\hline Turma & $\begin{array}{l}\text { P-valor } \\
\mathrm{N}\end{array}$ & \begin{tabular}{|l}
0 \\
29534
\end{tabular} & & & & & & & \\
\hline Absenteísmo & $\begin{array}{l}\text { Coeficiente Correlação } \\
\text { P-valor } \\
\mathrm{N}\end{array}$ & $\begin{array}{l}-0,412 * * \\
0 \\
29534\end{array}$ & $\begin{array}{l}0,027 * * \\
0 \\
29839\end{array}$ & $\begin{array}{l}1 \\
29839\end{array}$ & & & & & \\
\hline Turno & $\begin{array}{l}\text { Coeficiente Correlação } \\
\text { P-valor } \\
\text { N }\end{array}$ & $\begin{array}{l}0,134^{* *} \\
0 \\
29534\end{array}$ & $\begin{array}{l}0,256^{* *} \\
0 \\
29839\end{array}$ & $\begin{array}{l}0,026^{* *} \\
0 \\
29839\end{array}$ & $\begin{array}{l}1 \\
29839\end{array}$ & & & & \\
\hline Período & $\begin{array}{l}\text { Coeficiente Correlação } \\
\text { P-valor } \\
\text { N }\end{array}$ & $\begin{array}{l}0,216^{* *} \\
0 \\
29534\end{array}$ & $\begin{array}{l}-0,219 * * \\
0 \\
29839\end{array}$ & $\begin{array}{l}0,063 * * \\
0 \\
29839\end{array}$ & $\begin{array}{l}0,223 * * \\
0 \\
29839\end{array}$ & $\begin{array}{l}1 \\
29839\end{array}$ & & & \\
\hline $\mathrm{CH} 30$ & $\begin{array}{l}\text { Coeficiente Correlação } \\
\text { P-valor } \\
\text { N }\end{array}$ & $\begin{array}{l}0,099 * * \\
0 \\
29534\end{array}$ & $\begin{array}{l}-0,029 * * \\
0 \\
29839\end{array}$ & $\begin{array}{l}-0,128 * * \\
0 \\
29839\end{array}$ & $\begin{array}{l}-0,033^{* *} \\
0 \\
29839\end{array}$ & $\begin{array}{l}-0,205 * * \\
0 \\
29839\end{array}$ & $\begin{array}{l}1 \\
29839\end{array}$ & & \\
\hline $\mathrm{CH} 60$ & $\begin{array}{l}\text { Coeficiente Correlação } \\
\text { P-valor } \\
\text { N }\end{array}$ & $\begin{array}{l}0,024 * * \\
0 \\
29534\end{array}$ & $\begin{array}{l}-0,130^{* *} \\
0 \\
29839\end{array}$ & $\begin{array}{l}0,075^{* *} \\
0 \\
29839\end{array}$ & $\begin{array}{l}0,075 * * \\
0 \\
29839\end{array}$ & $\begin{array}{l}0,317 * * \\
0 \\
29839\end{array}$ & $\begin{array}{l}-0,728^{* *} \\
0 \\
29839\end{array}$ & $\begin{array}{l}1 \\
29839\end{array}$ & \\
\hline $\mathrm{CH} 90$ & $\begin{array}{l}\text { Coeficiente Correlação } \\
\text { P-valor } \\
\text { N }\end{array}$ & $\begin{array}{l}-0,151 * * \\
0 \\
29534\end{array}$ & $\begin{array}{l}0,222 * * \\
0 \\
29839\end{array}$ & $\begin{array}{l}0,042 * * \\
0 \\
29839\end{array}$ & $\begin{array}{l}-0,069 * * \\
0 \\
29839\end{array}$ & $\begin{array}{l}-0,215^{* *} \\
0 \\
29839\end{array}$ & $\begin{array}{l}-0,130 * * \\
0 \\
29839\end{array}$ & $\begin{array}{l}-0,586 * * \\
0 \\
29839\end{array}$ & $\begin{array}{l}1 \\
29839\end{array}$ \\
\hline
\end{tabular}

Variável de interesse: nota final de cada disciplina.

**O nível de correlação significativo é 0,01

Fonte: Dados da Pesquisa. 


\section{O ABSENTEÍSMO ACADÊMICO E SUAS CONSEQUÊNCIAS MAIS ÓBVIAS DOI: http://dx.doi.org/10.5007/1983-4535.2017v10n1p172}

É interessante observar, na terceira coluna da Tabela 7, que as correlações entre absenteísmo as demais variáveis pesquisadas são todas significativas ao nível de 1\%.

Verifica-se, inicialmente, a correlação negativa entre desempenho acadêmico e tamanho da turma, tendo em vista que, quanto menor a turma, maior o desempenho, ou seja, os alunos que estudam em turmas muito grandes, em média, têm desempenhos inferiores. A esse respeito, o estudo de Ferreira (2015) também encontrou relação significativamente negativa entre a quantidade de alunos participantes por instituição no ENADE 2012 e o respectivo desempenho da IES na referida avaliação.

Verifica-se também correlação negativa entre desempenho acadêmico e absenteísmo, a qual o apresentou o coeficiente mais forte $(-0,412)$. Esses resultados estão de acordo com os estudos de Sancovschi, Fernandes e Siqueira (2009) e Nogueira et al. (2012). Essa relação pode ser justificada pelo fato de a presença em sala de aula estar diretamente ligada ao fato dos discentes poderem tirar dúvidas, como foi apresentado por Souto-Maior et al. (2011), receberem feedback imediato, citado por Stuart (2004), e desenvolverem melhor as atividades que lhe são oferecidas.

Em relação ao turno, foi constatado que o turno noturno apresenta desempenho maior que o turno diurno. Esses resultados se contrapõem aos achados de Souto-Maior et al. (2011), uma vez que, naquela pesquisa, os alunos do turno noturno obtiveram notas menores. No entanto, corroboram os achados de Moura, Miranda e Pereira (2015).

Quanto ao período, foi verificado que os alunos dos períodos mais avançados obtiveram notas maiores que os alunos dos primeiros períodos. Esses resultados corroboram a pesquisa de Araújo, Camargos e Camargos (2011), visto que, segundo os autores, os alunos dos primeiros períodos ainda estão indecisos quanto à escolha da profissão. Enquanto os alunos do meio do curso em diante levam o curso mais a sério e apresentam notas maiores, em virtude do maior interesse em disciplinas relacionadas às áreas que atuam ou pretendem atuar.

Em termos de carga-horária, nota-se que houve correlação positiva entre desempenho e as disciplinas com cargas-horárias menores, com 30 ou 60 horas. Também foi verificada correlação significativa e negativa entre desempenho e as disciplina com 90 horas. A esse respeito, é importante frisar que as disciplinas que têm carga-horária de 90 horas na instituição pesquisada são aquelas tidas como mais difíceis pelos alunos, quais sejam: Contabilidade Introdutória I; Contabilidade Introdutória II; e Matemática Financeira. 
Ao finalizar a análise da terceira coluna da Tabela 7, nota-se que todas as variáveis analisadas apresentaram correlação significativa com desempenho acadêmico, mas o absenteísmo, foco deste estudo, apresentou o maior coeficiente de correlação com o desempenho (-0,412). É importante mencionar que, no estudo sobre determinantes do ENADE 2012 na área contábil, realizado por Ferreira (2015), os coeficientes de correlação das 33 variáveis analisadas são todos inferiores a esse acima apresentado, o que reforça a importância dessa variável na explicação do desempenho acadêmico na área contábil.

Quanto à quarta coluna da Tabela 7 , ressalta-se a importância de discutir a relação entre absenteísmo e tamanho da turma. Novamente, verifica-se que, quanto maior a turma, maior o número de faltas. Segundo Souto-Maior et al. (2011), quanto maior a turma, maior o barulho, além disso, alguns alunos ficam distantes do quadro e podem não enxergar o que está escrito, tornando-se mais difícil a comunicação com o professor. Tais fatores poderiam contribuir para a queda no desempenho geral da turma.

Na quinta coluna da Tabela 7, pode-se verificar a correlação significativa entre turno noturno e absenteísmo, pois os alunos do período noturno faltam mais que os alunos do diurno. Essa situação pode ser justificada pelo fato de que os alunos do noturno trabalham ou fazem estágio, mas, de acordo com a pesquisa de Sancovschi, Fernandes e Siqueira (2009), o empenho dos alunos nos estágios não apresenta relação significativa com a quantidade de faltas.

Com relação à carga horária, foi constatado que, nas disciplinas de 30 horas aula, os alunos faltam menos que nas aulas com carga horária de 60 e 90 horas. Isso pode ser explicada pelo fato de a quantidade de aulas serem menores, uma vez que a análise do absenteísmo foi feita em relação à carga-horária.

Por fim, foi realizada a análise de evasão, considerando a situação dos alunos em cada uma das disciplinas investigadas, conforme apresentado na Tabela 8.

Tabela 8 Evasão por Discente/Disciplina.

\begin{tabular}{lccc}
\hline Situação & Frequência & \multicolumn{2}{c}{ Evasão } \\
\hline Aprovado & 24.835 & 1.131 & $4,55 \%$ \\
Dispensado & 72 & 10 & $13,89 \%$ \\
Trancamento Parcial & 233 & 41 & $17,60 \%$ \\
Reprovado por Nota & 2.515 & 323 & $12,84 \%$ \\
Reprovado por Frequência & 2.184 & 719 & $32,92 \%$ \\
\hline Total & 29.839 & 2.224 & $7,45 \%$ \\
\hline
\end{tabular}

Fonte: Dados da Pesquisa. 
Como pode ser notado na Tabela 8 , o percentual de evasão dos alunos pesquisados no período foi de 7,5\%, ou seja, das 29.839 matrículas em disciplinas investigadas, 2.224 foram realizadas por alunos que vieram a evadir posteriormente. Esses alunos foram aprovados em várias disciplinas, como mostrado na primeira linha, mas no decorrer do curso acabaram desistindo de se formar. É surpreendente verificar que, dentre os alunos evadidos, 32,9\% (quase um terço) já foram reprovados anteriormente por frequência em alguma disciplina. Ou seja, entre os reprovados por frequência estão os maiores percentuais de evasão. Esses resultados atestam a segunda consequência óbvia do absenteísmo, qual seja a evasão.

\section{CONSIDERAÇÕES FINAIS}

Este artigo analisou alguns fatores que afetam o desempenho acadêmico, como tamanho da turma, turno, período, carga horária e absenteísmo, com ênfase no último. Os dados analisados foram coletados de documentos de discentes de graduação do curso de Ciências Contábeis em uma instituição pública brasileira. Foram analisadas 715 disciplinas cursadas por 1.525 estudantes entre os anos de 2009 e 2013, totalizando 29.839 observações.

Os resultados obtidos apontam que a presença dos docentes em sala de aula e seu papel na vida acadêmica é importante para os discentes, visto que a assiduidade dos alunos em sala interfere diretamente no desempenho acadêmico dos mesmos. É importante que os professores estimulem os alunos e encontrem formas para motivá-los cada vez mais a frequentarem as aulas.

Verificou-se também que, dentre as variáveis analisadas, a que obteve o maior coeficiente de correlação com desempenho acadêmico foi absenteísmo, constatando que, quanto maior a frequência em sala de aula, maior a probabilidade de obter notas maiores, o que corrobora os achados de Nogueira et al. (2012); Rodgers (2001); Romer (1993); SoutoMaior et al. (2011).

Outras variáveis que afetam o desempenho dos discentes também foram diagnosticadas, estando o tamanho da turma entre elas. Assim, quanto menor a turma, maior o desempenho, já que, em turmas maiores, os professores nem sempre conseguem responder todas as dúvidas dos alunos e, em turmas maiores, é mais fácil os alunos se dispersarem e perderem a explicação. Em relação ao período em que estão matriculados, foi constatado que, nos períodos mais avançados, os alunos obtiveram notas maiores, mas faltam mais que os alunos dos períodos iniciais. Esses dados podem ser explicados pelo fato de, nos últimos 
períodos, as matérias ministradas estarem mais relacionadas com o meio profissional e os alunos já inseridos no mercado de trabalho.

Assim, partindo da ideia predominante no senso comum, de que o absenteísmo é prejudicial ao processo de ensino e aprendizagem, o presente estudo chega a dois achados importantes e, diríamos, óbvios: o absenteísmo tem consequências diretas no desempenho acadêmico e nos níveis de evasão nos cursos presenciais de graduação em Ciências Contábeis. Portanto, atenção especial deve ser dirigida ao fenômeno por parte dos gestores educacionais e dos professores no sentido de estabelecerem políticas, mecanismos e métodos de ensino que estimulem a frequência dos alunos.

No entanto, os maiores interessados nos resultados deste estudo são os próprios alunos. É bastante provável que a grande maioria deles não tenha consciência dos reflexos que a simples falta às aulas pode ocasionar em sua vida estudantil e, principalmente, profissional. A dedicação aos estudos poderá ter benefícios impossíveis de se mensurar, já a sua ausência poderá promover o oposto.

Foram encontrados poucos estudos que abordam absenteísmo e desempenho dos discentes, notadamente, na área contábil. Esse fato é uma limitação da pesquisa, já que não foram encontrados tantos estudos para estabelecer comparações e saber se os resultados encontrados seriam semelhantes aos de outras instituições do Brasil e do mundo.

Nesse sentido, sugere-se para estudos futuros, análises em outras regiões e em outras instituições (particulares, por exemplo) para que outras comparações possam ser realizadas. Sugere-se, também, a realização de levantamentos entre os alunos para entender os motivos que os levam a não comparecerem nas aulas obrigatórias, com a finalidade de se buscarem alternativas para estimular o seu comparecimento às aulas ministradas.

\section{REFERÊNCIAS}

ARAÚJO, E. A. T; CAMARGoS, M. A., CAMARGOS, M. C. S. Desempenho acadêmico de discentes do curso de ciências contábeis: uma análise dos seus fatores determinantes em uma IES privada. In: ENANPAD, 35, 2011, Rio de Janeiro. Anais... Rio de Janeiro: ANPAD. 2011.

FARO, Divisão de Acção Social, Análise da relação entre o perfil psicossocial do aluno e o abandono escolar. Projecto "Integrar para Educar"- Programa Ser Criança. Ministério do Trabalho e Solidariedade Social, da Câmara Municipal de Faro. Portugal, 2007. 
FERREIRA, M. A. Determinantes do desempenho discente no ENADE em cursos de Ciências Contábeis. 123 p. Dissertação de Mestrado. Faculdade de Ciências Contábeis da Universidade Federal de Uberlândia. 2015.

GIL, A. C. Métodos e técnicas de pesquisa social. 5. ed. São Paulo: Atlas. 1999.

GONZÁLEZ, M. T. G. Absentismo escolar: posibles respuestas desde el centro educativo.

Revista Iberoamericana sobre Calidad, Eficacia y Cambio en Educación, v. 12, n. 2, p. 527. 2014.

MIRANDA, G. J.; LEMOS, K. C. S.; PIMENTA, A. S. O.; FERREIRA, M. A. Determinantes do desempenho acadêmico na área de negócios. Meta: Avaliação, v. 7, p. 175-209, 2015.

MOURA, A. C. R.; MIRANDA, G. J.; PEREIRA, J. M. Desempenho acadêmico em ciências contábeis: turno noturno versus diurno. Enfoque: Reflexão Contábil, v. 34, n. 1, p. 57-70.

MUNHOZ, A. M. H. Uma análise multidimensional da relação entre inteligência e desempenho acadêmico em universitários ingressantes. Tese de Doutorado, Faculdade de Educação da Universidade Estadual de Campinas, Campinas. 2004.

NOGUEIRA, D. R.; TAKAMATSU, R. T.; COSTA, M. J.; REIS, L. G. Fatores que impactam o desempenho acadêmico: uma análise com discentes do curso de ciências contábeis no ensino presencial. In: CONTABILIDADE PARA O DESENVOLVIMENTO SUSTENTÁVEL, 19. Anais... Belém: Congresso Brasileiro de Contabilidade. 2012.

PAISEY, C.; PAISEY, N. J. Student attendance in an accounting module - reasons for nonattendance and the effect on academic achievement at a Scottish university. Accounting Education. v. 13, n. 1, p. 39-53. 2004.

RICHARDSON, R. J. Pesquisa Social: métodos e técnicas. 3. ed. São Paulo: Atlas. 2011.

RODGERS, J. R. A panel-data study of effect of student attendance on university performance. Australian Journal of Education. v. 45, n. 3, p. 284-295. 2001.

ROMER, D. Do students go to class? Should they?. Journal of Economic Perspectives. v. 7, n. 3, p. 167-174. 1993.

SANCOVSCHI, M.; FERNANDES, L. J. D.; SIQUEIRA, J. R. M. Custos pessoais do empenho imoderado de alunos de cursos de graduação em administração nos estágios: a relação entre empenho dos alunos, sobrecarga de trabalho, estresse no trabalho, e aspectos significativos da vida acadêmica. In: ENANPAD, 33., 2009, São Paulo. Anais..., São Paulo: ANPAD. 2009.

SCHMULIAN, A.; COETZEE, S. Class absenteeism: reasons for non-attendance and the effect on academic performance. Accounting Research Journal. v. 24, n. 2, p. 178-194. 2011.

STEENKAMP, L. P.; BAARD, R. S.; FRICK, B. L. Factors influencing success in first-year accounting at a South African university: a comparison between lecturers' assumptions and 
students' perceptions. South African Journal of Accounting Research (Sajar), v. 23, n. 1, p. 113-140. 2009.

STUART, I. The impact of immediate feedback on student performance: an exploratory study in Singapore. Global Perspectives on Accounting Education, v. 1, p. 1-15. 2004.

SOUTO-MAIOR, C. D.; BORBA, J. A.; KNUPP, P. S.; CROLL, E. S. Análise de fatores que afetam o desempenho de alunos de graduação em administração e contabilidade na disciplina de pesquisa operacional. In: ENANPAD, 35, 2011, Rio de Janeiro. Anais... Rio de Janeiro: ANPAD. 2011.

TEIXEIRA, A. A. C. The impact of class absenteeism on undergraduates academic performance: evidence from an elite economics school in Portugal. FEP Working Papers. v. 1 n. 503, p. 1-17. 2013. 